\title{
An Annual and Seasonal Characterisation of Winery Effluent in South Africa
}

\author{
C.M. Sheridan ${ }^{1 *}$, D. Glasser ${ }^{1}$, D. Hildebrandt ${ }^{1}$, J. Petersen $^{2}$ and J. Rohwer ${ }^{3}$
}

(1) School of Chemical and Metallurgical Engineering, University of the Witwatersrand, Private Bag 3, Wits 2050, South Africa

(2) Centre for Bioprocess Engineering Research (CeBER), Department of Chemical Engineering, University of Cape Town, Private Bag X6, Rondebosch 7701, South Africa

(3) Triple-J Group for Molecular Cell Physiology, Department of Biochemistry, Stellenbosch University, Private Bag X1, Matieland 7602, South Africa

Submitted for publication: March 2010

Accepted for publication: October 2010

Key words: Winery, effluent, annual, seasonal, composition

\begin{abstract}
Winery effluent is known to have a high chemical oxygen demand (COD) and a low pH. In this study, we extensively analysed effluent from two cellars and studied the temporal changes over the duration of a harvest and the duration of a year. We found that ethanol contributes approximately $85 \%$ to $90 \%$ of the COD of raw winery effluent, with acetic acid being the next significant contributor. The $\mathrm{pH}$ showed some dependence on the concentration of acetic acid. The concentration of sodium in the effluent is strongly dependent on the cleaning regime in place at the cellar, and the concentration of potassium has been shown to be linked to the spillage of juice, wine or lees. The data and correlations presented here could allow for an artificial effluent to be prepared easily for research purposes.
\end{abstract}

\section{INTRODUCTION}

The process of winemaking produces a large quantity of effluent, in the order of one million cubic metres per annum in South Africa (Sheridan, 2003). Historically, this effluent was irrigated onto pastures, evaporated, or drained into the nearest river. In recent years, the Department of Water Affairs and Environment (DWAE) has made significant progress in tightening SA water law, and in increasing water consumer compliance with this law. To this end, most winemakers and wineries have established some form of effluent treatment rather than simple disposal, even if that treatment is just irrigation of pastures. The current laws in place allow for disposal by irrigation, provided there is continuous measurement of effluent strength and of certain aspects relating to its composition. Under SA law (Government Gazette, 2001), winery effluent is regarded as biodegradable industrial wastewater, and as such there are five parameters that must be reported: chemical oxygen demand (COD), $\mathrm{pH}$, electrical conductivity (EC), sodium adsorption ratio (SAR) and faecal coliforms. If the effluent is released into a river, there are additional parameters that need to be measured, and the limits are stricter (Government Gazette, 2001). In compliance with the law, these five measures of winery effluent are commonly reported. Any other chemical characteristics are rarely mentioned, however, and this can be a problem for the detailed design of an effluent treatment system.

A number of processes could be considered for the treatment of winery effluents, such as anaerobic digesters, aerobic digesters, sequencing batch reactors and rotating biological contactors, among others. A quantitative description of such processes, especially modelling of the kinetics of various biodegradation processes, is needed for equipment design and process evaluation.

However, in order to achieve this, additional information on the chemical composition of the effluent is required. Chemical oxygen demand (COD) and sodium adsorption ratio (SAR), as lumped parameters, are not well suited to accurate modelling because they do not provide detailed information on what comprises them. For example, a certain quantity of glucose or lignin may have a similar COD, but the glucose is much more readily biodegradable than the lignin. Thus, substantially different rate constants for the reduction of the COD would be found in each case. It is common practice in the literature to specify a biodegradation rate constant for the reduction of COD (or biological oxygen demand, BOD) for a given effluent (Wood, 1995; Kadlec \& Knight 1996; Shepherd et al., 2001), and to utilise these in process models for the design of effluent treatment technologies.

In this study, the effluent from two wineries was investigated. Effluent from the first winery (Cellar 1) was characterised over the duration of a year. The winery is typical of the Stellenbosch region of South Africa. It is a small family business that presses approximately 700 tons per annum of various grape varietals. The process is traditional, with both open concrete fermenters and jacketed stainless steel tanks being used to produce both red and white wine.

The second winery (Cellar 2) forms part of an experimental farm belonging to the Agricultural Research Council of South Africa (ARC). Red and white wines are produced in this cellar.

*Corresponding author: craig.sheridan@wits.ac.za

Acknowledgements: The authors would like to thank the Water Research Commission, for their generous funding of project K5 1544; the National Research Foundation, for financial assistance; the Agricultural Research Council-Nietvoorbij in Stellenbosch, for the extended use of their constructed wetland for the duration of the study; and Professor Stephanie Burton, CPUT, for her guidance and assistance 
Within this overlying research infrastructure, it was possible to sample the effluent on a daily basis and to construct a profile of the effluent for the duration of a harvest season. In this case, the season was from the end of January 2005 to the end of March 2005. This harvest was particularly short (normally the harvest lasts for three months) and almost no rain fell in the two-month period. This was advantageous, as it allowed for accurate sampling because there was no dilution effect through rainwater mixing with the samples.

\section{MATERIALS AND METHODS \\ Sampling protocol}

Cellar 1 is built on a slope and the various drains in the cellar exit the building at different locations. These drainage streams converge some distance from the cellar, and thus particular care was required to ensure that the samples were representative of the entire winemaking process. To achieve this, the samples were taken at a point where all the effluent streams from the winery were combined. Grab samples, comprising $500 \mathrm{~mL}$ aliquots, were taken approximately every fortnight during the harvest season, and monthly outside of the harvest season. These samples were analysed for a number of different chemical constituents (see below).

For Cellar 2, grab samples were taken daily for the duration of the 2005 harvest (from 31 January 2005 to 31 March 2005), with the exception of on weekends and long weekends. The 500 $\mathrm{mL}$ aliquots were taken from a surge tank prior to treatment and were thus deemed to be representative samples.

\section{Analytical methods for effluent characterisation}

The COD was measured using a Merck COD Cell test (1.14555.001) and the Merck Spectroquant spectrophotometer. Metals in solution were measured by atomic absorption (AA) using a Varian SpectrAA flame spectrophotometer. Gas mixtures of acetylene/air were used for sample combustion, and detection wavelengths for each of the metals identified were specified in the user's manual. Inorganic anions were analysed with a high performance liquid chromatography (HPLC) with a Waters IC-Pak (HR 4.6x75mm) Anion Column, using a conductivity detector (parameters used were: Column $\mathrm{T}=$ ambient, $1.5 \mathrm{~mL} / \mathrm{min}$, mobile phase, $3.6 \mathrm{mM}$ sodium carbonate). Some organic components initially were identified and quantified using the HPLC method described above. Thereafter, all organic components were identified using GCMS, with a Restek RTX Capillary column $(60 \mathrm{~m}$ by $250 \mu \mathrm{m})$ and a T-initial of $70^{\circ} \mathrm{C}$, ramped at $5^{\circ} \mathrm{C}$ per minute to $170^{\circ} \mathrm{C}$, with a second ramp of $10^{\circ} \mathrm{C} / \mathrm{min}$ to $280^{\circ} \mathrm{C}$. Routine analyses of those organic components identified as being the most abundant in the effluent were conducted using GC-FID, with a J \& W Scientific DB-Wax Column $\left(60 \mathrm{~m}\right.$ by $250 \mu \mathrm{m}$, T-initial of $40^{\circ} \mathrm{C}$ for $10 \mathrm{~min}$, ramped at $10^{\circ} \mathrm{C} / \mathrm{min}$ to $160^{\circ} \mathrm{C}$ ). The variance for this assay was 0.002 and the variance for the preparation of the samples was $0.046(n=3)$. Total phenol concentration was measured using the Folin Ciocalteau method (Cheung et al., 2003) measuring absorbance at a wavelength of $765 \mathrm{~nm}$.

\section{RESULTS AND DISCUSSION \\ Effluent composition}

In an initial investigation, the composition of the winery effluent at Cellar 2 was determined at the beginning of the
TABLE 1

The composition of winery effluent at Cellar 2 as determined by an initial investigation at the beginning of the harvest season.

\begin{tabular}{lccc}
\hline Component & $\begin{array}{c}\text { Concentration } \\
(\mathbf{m g} / \mathbf{L})\end{array}$ & $\begin{array}{c}\text { Standard } \\
\text { deviation }(\mathbf{m g} / \mathbf{L})\end{array}$ & Method \\
\hline $\mathrm{Zn}$ & 0.71 & 0.00497 & $\mathrm{AA}$ \\
$\mathrm{Mg}$ & 12.3 & 0.0123 & $\mathrm{AA}$ \\
$\mathrm{Ca}$ & 59.3 & 0.5337 & $\mathrm{AA}$ \\
$\mathrm{Na}$ & 54.5 & 0.109 & $\mathrm{AA}$ \\
$\mathrm{K}$ & 82.9 & 0.1658 & $\mathrm{AA}$ \\
$\mathrm{Cu}$ & 0.03 & 0.00612 & AA \\
$\mathrm{Fe}$ & 21.35 & 0.06405 & $\mathrm{AA}$ \\
$\mathrm{Mn}$ & 0.29 & 0.00203 & AA \\
$\mathrm{Cr}($ Total) & Not detected & Not detected & AA \\
$\mathrm{Pb}$ & 0.11 & 0.02541 & AA \\
$\mathrm{B}$ & Not detected & Not detected & AA \\
$\mathrm{As}$ & Not detected & Not detected & AA \\
$\mathrm{Glucose}$ & Not detected & Not detected & HPLC \\
Fructose & Not detected & Not detected & HPLC \\
$\mathrm{Citric}$ acid & Not detected & Not detected & HPLC \\
\hline
\end{tabular}

wine-producing season in order to identify the most significant components of winery effluent on the basis of concentration (Table 1) and their contribution to the COD. Na, K, Ca, Mg and Fe were the dominant metallic species and, more specifically, $\mathrm{Na}$ and $\mathrm{K}$ were identified as being the most important metallic components in winery effluent based on prevalence. Although $\mathrm{Ca}$ was more abundant than $\mathrm{Na}$, it was excluded because it occurred naturally in similar concentrations in the groundwater at this site. This is in agreement with data obtained by Sheridan et al. (2005) and Bustamante et al. (2005), who found these two components to be prolific in winery effluent.

No glucose was detected in any of the samples tested over the course of this study, although other authors (Malandra et al., 2003; Colin et al., 2005) found both fructose and glucose in effluent samples.

A GC-MS analysis indicated the following components to be the primary organic constituents in the effluent study: ethanol, acetic acid (ethanoic acid), i-propanol, i-propanoic acid, i-butyric acid (iso-butanoic acid) and valeric acid (isopentanoic acid). These results are in agreement with data from Colin et al. (2005), who found that ethanol was the main organic component of winery effluent.

The total polyphenol content of the winery effluent was measured (using the Folin Ciocalteau method) and was found to be between $17.72 \pm 2.10 \mathrm{mg} / \mathrm{L}$ and $37.08 \pm 10.29 \mathrm{mg} / \mathrm{L}$ (two separate samples taken on different days, three replications of each sample). This variation is likely due to the samples being taken on different days. These concentrations are in agreement with data presented by Malandra et al. (2003) and Petruciolli et al. (2001). Relative to the dominant organic components, these levels are insignificant on the basis of concentration. Based on the findings of earlier studies (Chapman, 1996; Radford, 2002; Sheridan, 2003), nitrogen and phosphorus are not significant components of winery wastewater relative to the 


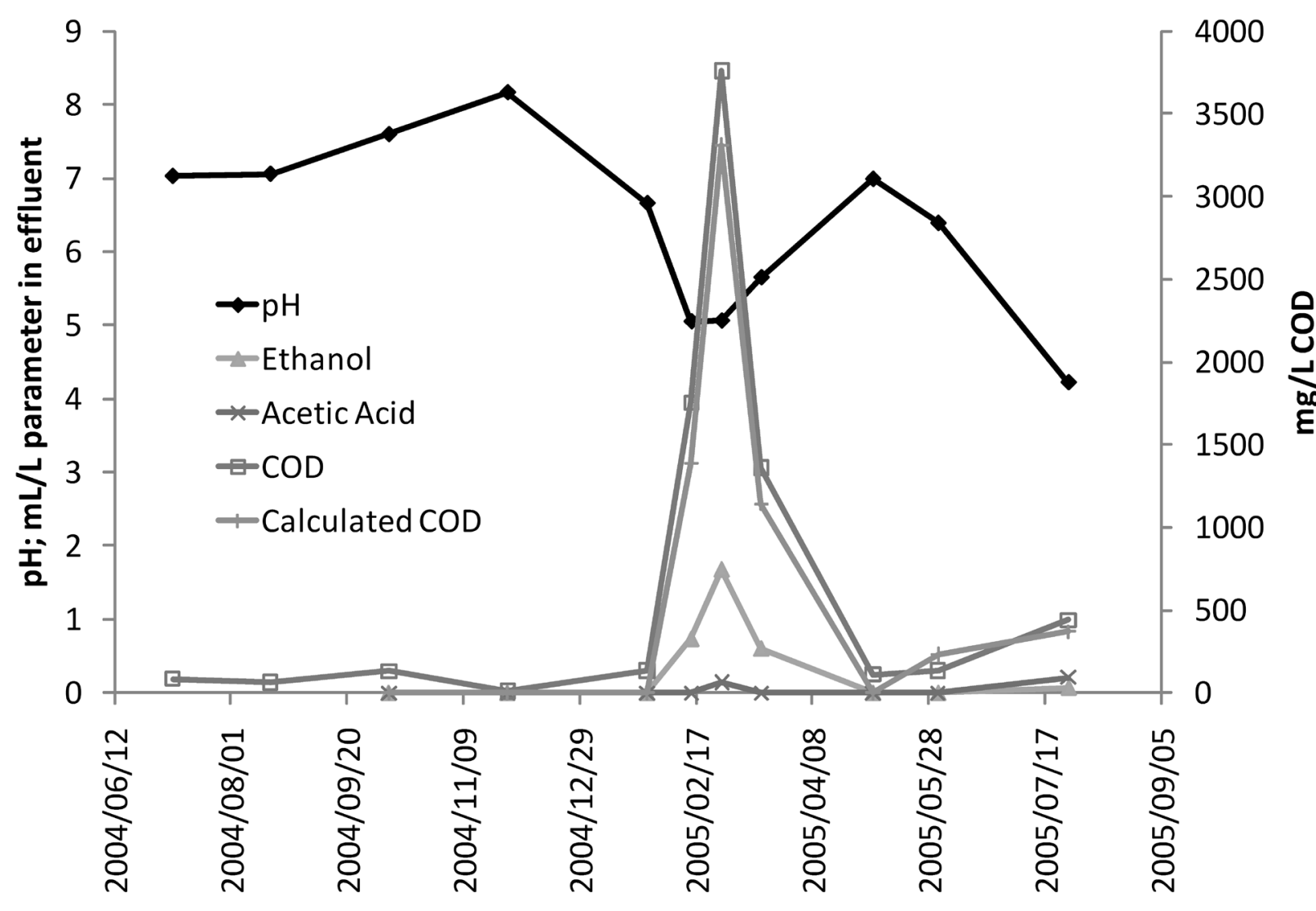

FIGURE 1

Organic components (ethanol and acetic acid) overlaid on pH and COD at Cellar 1.

other compounds.

Using these preliminary findings, and based on their abundance, the following components were selected as being important components for the purpose of modelling the degradation of winery effluent: $\mathrm{pH}, \mathrm{Na}, \mathrm{K}$, ethanol, propanol, acetic acid, propanoic acid and butyric acid. COD was also measured for comparison.

\section{Annual monitoring of the effluent at Cellar 1}

The composition of the effluent at Cellar 1 was plotted over the course of a year (Fig. 1). Individual components of the effluent are discussed below.

\section{pH of the effluent (Cellar 1)}

The $\mathrm{pH}$ was expected to be lower during harvest than at other times of the year due to the low $\mathrm{pH}$ of grape juice and wine (typically 3 to 4). The effluent was shown to have a $\mathrm{pH}$ of approximately 5 during the peak harvest period. The $\mathrm{pH}$ was unexpectedly low in August 2005, however, and this was ascribed to an observed once-off pulse of high-strength effluent, which was not typical during this period and possibly was due to wine-handling operations (wine is naturally of a low $\mathrm{pH}$ and ethanol is degraded to acetic acid, further reducing the $\mathrm{pH}$ ).

\section{Concentration of ethanol and propanol (alcohols) (Cellar 1)}

The ethanol concentration ranged from not detectable (indicated as $0 \mathrm{~mL} / \mathrm{L}$ ) to $1.7 \mathrm{~mL} / \mathrm{L}$, which is approximately one third of that found by Colin et al. (2005). Although propanol was defined as an abundant component on the basis of the initial characterisation, it was not detected in any of the samples of this particular winery effluent. This is indicative of the variability of the winemaking process.

\section{Occurrence of carboxylic acid (Cellar 1)}

In most of the samples the carboxylic acid levels were below detection and, where found, they rarely exceeded $0.2 \mathrm{~mL} / \mathrm{L}$. Propanoic acid and butyric acid are not shown in Fig. 1, since their concentrations rarely exceeded $0.2 \mathrm{~mL} / \mathrm{L}$. The contribution of carboxylic acids to the $\mathrm{pH}$ is significant, as is shown by the peak in August 2005, which brought the $\mathrm{pH}$ of the effluent down to 4.2. Whilst acetic acid is relatively biodegradable, it contributes to the environmental burden at these maximum observed concentrations, to the extent that the effluent is too acidic for general disposal under SA law (Government Gazette, 2001). Propanoic and butyric acid are primarily important because they contribute significantly to the malodour of winery effluent. It was noted that the effluent had a particularly unpleasant odour in early June 2005, the same time that a pulse of propanoic acid was recorded.

\section{Chemical oxygen demand (COD) (Cellar 1)}

In Fig. 1, the annual variation of the COD is shown as measured COD values and calculated COD values. COD is a measure of the oxygen that would be required to completely oxidise all constituents (organic and inorganic) of a given effluent. Thus, for an effluent that is primarily ethanol and ethanoic acid $(90 \%$ and more), Equations 1 and 2 could be used to estimate the 


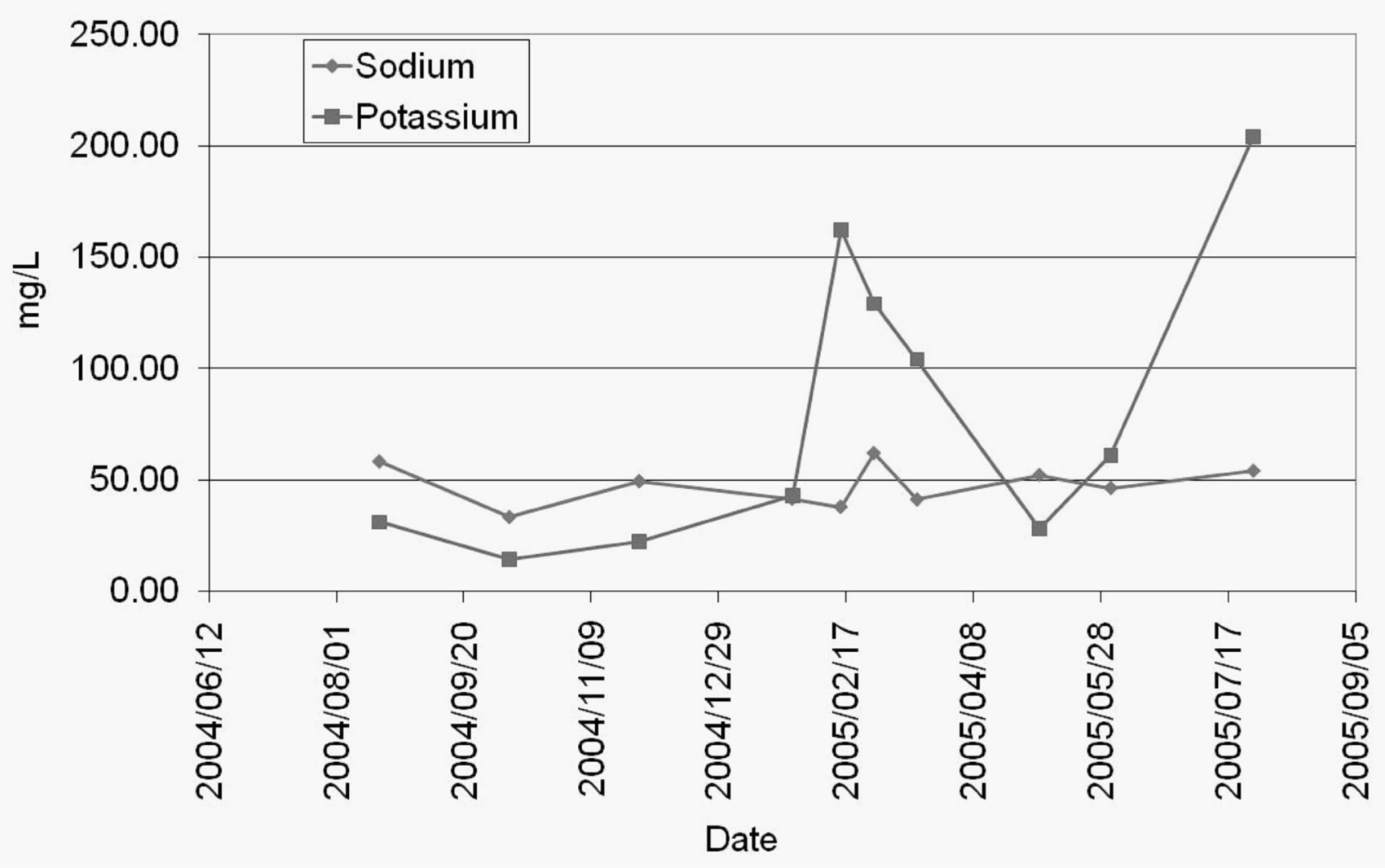

FIGURE 2

Cationic components in winery effluent measured over one year at Cellar 1.

COD by calculating the stoichiometric oxygen requirements for complete combustion:

$$
\mathrm{C}_{2} \mathrm{H}_{6} \mathrm{O}+3 \mathrm{O}_{2} \rightarrow 2 \mathrm{CO}_{2}+3 \mathrm{H}_{2} \mathrm{O} \quad \text { Equation } 1
$$

(ethanol oxidises to carbon dioxide and water)

$$
\begin{aligned}
& \mathrm{C}_{2} \mathrm{H}_{4} \mathrm{O}_{2}+2 \mathrm{O}_{2} \rightarrow 2 \mathrm{CO}_{2}+2 \mathrm{H}_{2} \mathrm{O} \\
& \text { (ethanoic acid oxidises to carbon dioxide and water) }
\end{aligned}
$$

Thus, the volumetric concentrations of ethanol and ethanoic acid can be converted to molar concentrations, the molar quantity of oxygen required for complete oxidation can be calculated, and this can be converted to a mass-based oxygen requirement relative to volume, such as $\mathrm{mg} / \mathrm{L}$, which is the norm for expressing COD. This is referred to as the calculated COD, as opposed to the measured COD, for which one utilises a reaction kit. This measurement is discussed in Methods. The COD of the effluent peaked in mid-March (which is mid-harvest) and decreased for the rest of the year; this is in common with the findings of others (Malandra et al., 2003; Sheridan, 2003; Colin et al., 2005). The maximum concentration found (3800 mg/L) is also in the expected range for a cellar of this size (Sheridan, 2003).

Because legislation focuses primarily on COD (with an upper legislative disposal limit of $5000 \mathrm{mg} / \mathrm{L}$ ) and not on the specific organic components of the effluent, the calculated COD was compared to the measured COD. It was found that ethanol was the most important contributor to the effluent COD and, together with acetic acid, accounted for $86 \%$ of the measured COD (ethanol contributed $84 \%$ of the COD in this sample, and acetic acid 2\%). This is in agreement with the findings of Colin et al. (2005).

\section{Metallic components of Cellar 1 effluent}

Sodium and potassium were found to be the most prevalent metallic species in the initial effluent samples and were therefore investigated over the year. The results are shown in Fig. 2, and clear trends can be observed.

Potassium concentrations rose significantly during harvest and subsided to a base level after the harvest. Potassium is the primary cation in grapes, where it plays an important role in grapevine metabolism, and is the most important inorganic solute in plants (Marschner, 1983). This explains the rise in potassium levels in the effluent during the harvest period, and the subsequent drop once the juice and wine spillage cease after harvesting. The sodium levels, however, remained relatively constant over the course of a year. At the winery investigated, the sodium concentration of the fresh water was $37.70 \mathrm{mg} / \mathrm{L}$, and $\mathrm{Na}_{2} \mathrm{CO}_{3}$ is used for cleaning throughout the year. Since the same water source was used throughout the year, and the cleaning chemicals were also unchanged, there was no reason for the concentration of sodium to change. As was observed in the $\mathrm{pH}$ and levels of acetic acid, there was a spike of potassium in the effluent in August 2005, and all of these factors confirm a 


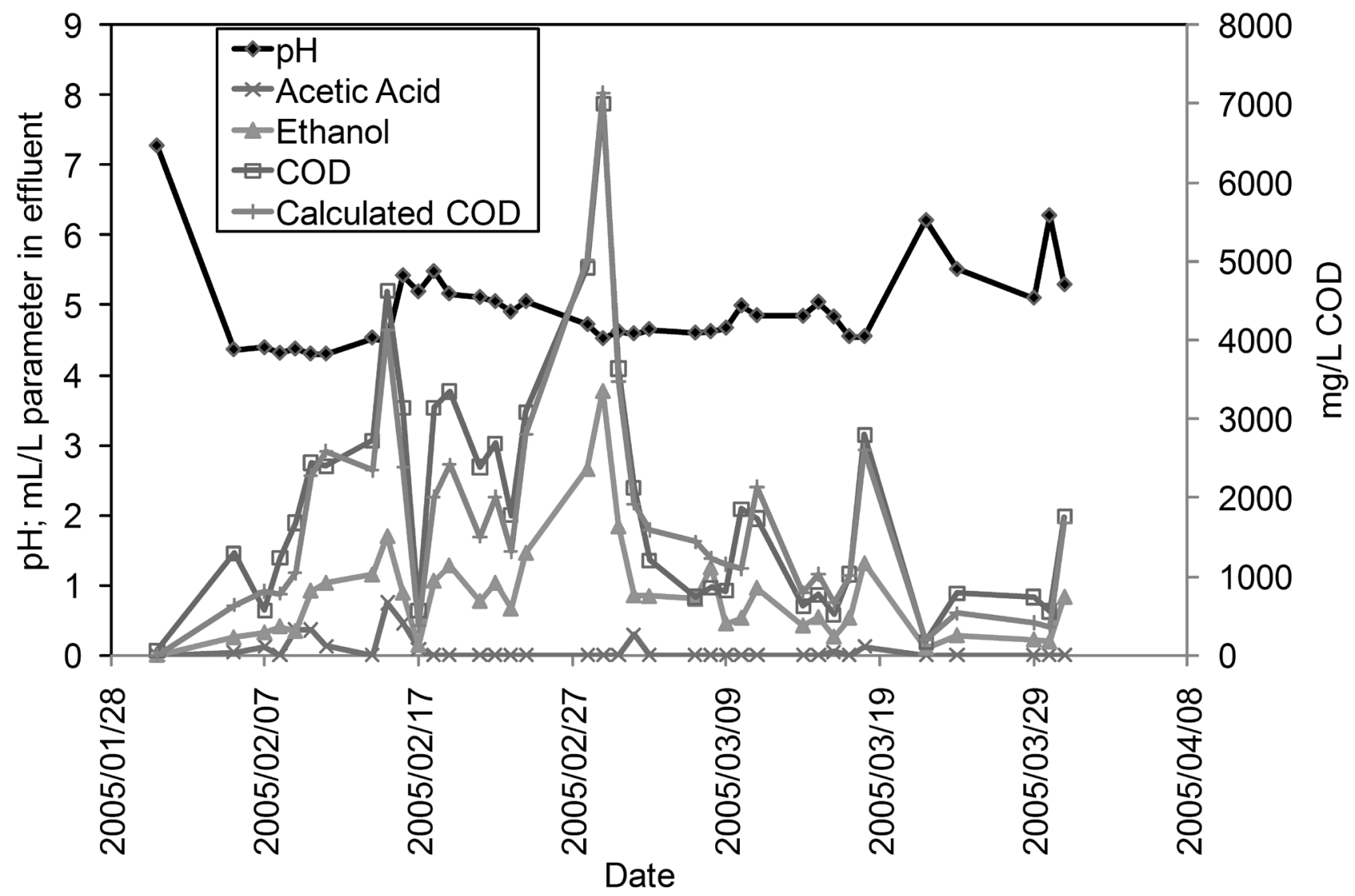

FIGURE 3

Organic components (ethanol and acetic acid) overlaid on $\mathrm{pH}$ and COD at Cellar 2

spill or release of wine (or possibly lees) just prior to sampling.

\section{Seasonal monitoring of the effluent at Cellar 2}

Since harvest time is the season of peak effluent strength, daily sampling of the effluent was conducted in order to gain an understanding of the daily variation at Cellar 2 . The composition of the effluent was plotted for the duration of a harvest season (Fig. 3). Individual components are discussed separately below.

\section{pH of the effluent (Cellar 2)}

The data indicate that the $\mathrm{pH}$ remained approximately constant and was not dependent on the time of sampling in the harvest period. The average $\mathrm{pH}$ was 4.94 , with a standard deviation of 0.61 , in comparison to the fresh water at this cellar, which has a $\mathrm{pH}$ of 7.63. The increase in $\mathrm{pH}$ at the end of March is related to the absence of harvesting over the Easter weekend, and the subsequent decline in activities towards the end of the harvest period.

\section{Concentration of ethanol and propanol (Cellar 2)}

The concentrations of ethanol and propanol in the effluent were analysed and the concentration of ethanol is shown in Fig. 1 for the period from early February to late March 2005. Propanol was detected occasionally, with values reaching up to $0.2 \mathrm{~mL} / \mathrm{L}$, but mostly remaining below the detection limit. The ratio of propanol to ethanol never exceeded 0.11 and was usually much lower, which implies that the quantity of propanol is insignificant in relation to the ethanol. The concentration of ethanol ranged from $0.2 \mathrm{~mL} / \mathrm{L}$ to $3.75 \mathrm{~mL} / \mathrm{L}$. This was significantly more than that found in Cellar 1, although Colin et al. (2005) detected levels of up to $4.9 \mathrm{~g} / \mathrm{L}$, which is approximately $50 \%$ more than what was detected in this study. This variation can be explained by the differences between cellars in terms of pressing different tonnages of grapes, and by water-handling practices.

\section{Carboxylic acids (Cellar 2)}

The concentration of acetic acid and ethanol in the effluent is shown in Fig. 3. This data is inconclusive: where there was a significant amount of ethanol in the effluent, there was no corresponding significant quantity of acetic acid. It was expected that the levels of acetic acid in the effluent would be related to those of ethanol, but the levels follow no clear pattern. The concentration of propanoic acid and butyric acid was generally low, with a maximum of $0.2 \mathrm{~mL} / \mathrm{L}$, but mostly below detection. As stated previously, these acids are not significant in terms of their contribution to the effluent COD, but they are significant environmentally because of their malodour. These findings are similar to the levels found in the effluent of Cellar 1 and also by Malandra et al. (2003).

\section{Chemical oxygen demand (COD) (Cellar 2)}

The COD of the raw effluent was assessed and is shown in Fig. 3. The graph depicts the increase in COD from pre-harvest until the middle of the harvest, and the decrease from the 


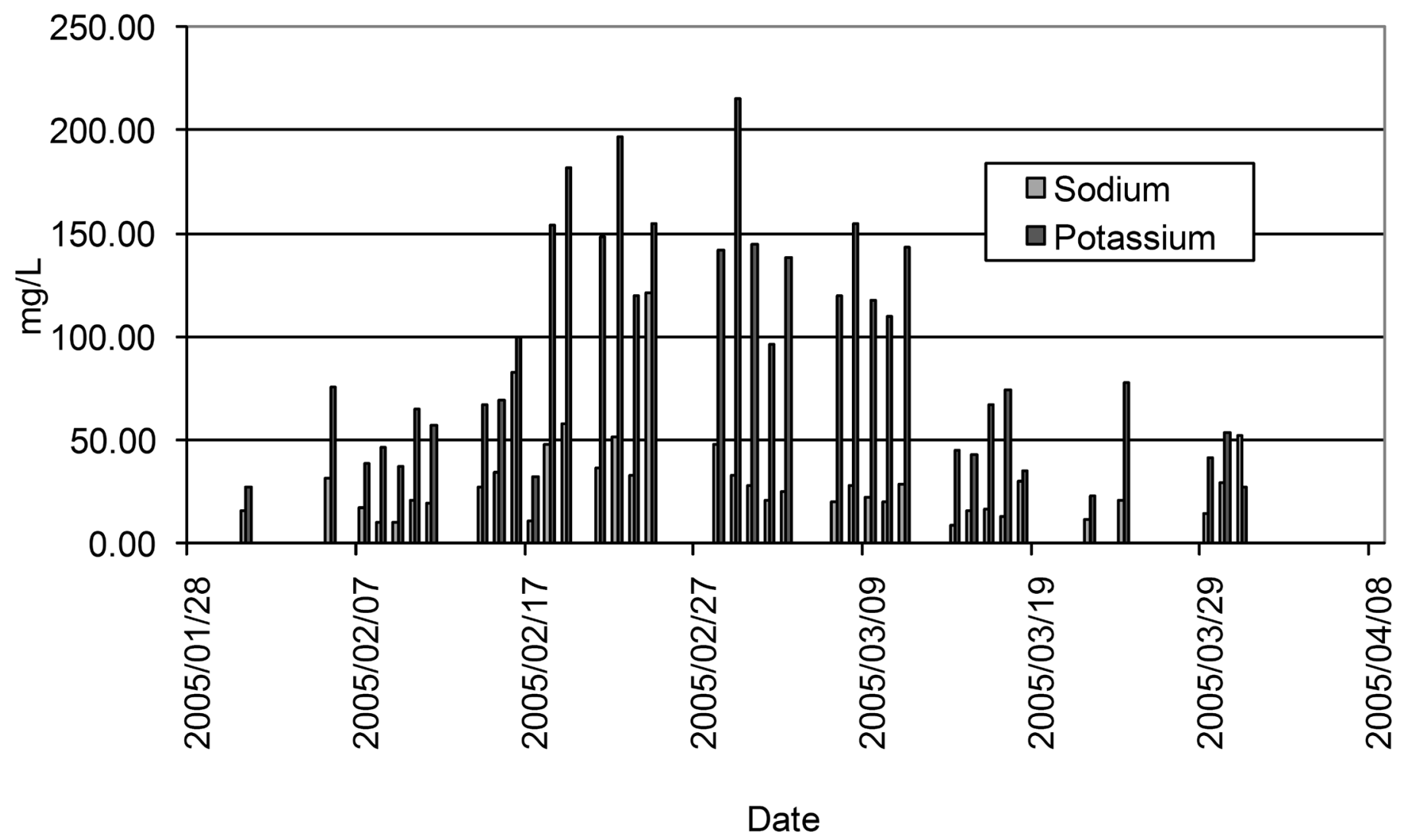

FIGURE 4

Cationic components in winery effluent measured over a harvest season at Cellar 2.

middle to the end of the harvest. This trend was expected, as the rate of processing increased from the start to the middle of the harvest and then decreased towards the end of the harvest. The calculated COD was found by calculating the stoichiometric oxygen requirements for the complete combustion of the organic components found in the effluent (as described earlier). The calculated COD includes the contributions by the organic components (ethanol, acetic acid, propanol, propanoic acid and butyric acid) and this method can account for approximately $91 \%$ of the COD of the raw effluent of Cellar 2. The implication is that the COD of the raw effluent from a winery can be calculated with reasonable accuracy if the ethanol and acetic acid concentrations of the effluent are known.

\section{Metallic components of Cellar 2 effluent}

Sodium and potassium were analysed routinely, based on the initial effluent determination discussed above, where these two cations were found to be the most abundant. The concentrations of sodium and potassium found in the effluent are shown in Fig. 4. Sodium was expected to arise in the effluent from cellar cleaning operations (caustic soda and sodium carbonate are used to clean dirty and stained tanks). Sodium levels varied widely, from $8.9 \mathrm{mg} / \mathrm{L}$ at the beginning of the harvest to a onceoff peak of $121 \mathrm{mg} / \mathrm{L}$ at the height of the harvest and around 20 $\mathrm{mg} / \mathrm{L}$ towards the end. The occasional spikes are consistent with cleaning activities in the cellar, which would occur on an ad hoc basis (as and when required). The average Na concentration over the harvest period was around $40 \mathrm{mg} / \mathrm{L}$.

The potassium levels were strongly affected by the time of sampling in the harvest season. Potassium values rose from $22.9 \mathrm{mg} / \mathrm{L}$ to $225 \mathrm{mg} / \mathrm{L}$ at the peak of the harvest, and then declined to background levels by the end of the harvest. This increase is consistent with the fact that potassium is a major inorganic constituent of grapes, and hence grape juice and wine (Sheridan, 2003). The potassium concentration range is within the range of values found by others (Malandra et al., 2003; Sheridan et al., 2005).

\section{Discussion of the variations in winery effluent}

Ethanol was the major constituent of winery effluent in Cellar 1 , contributing $86 \%$ of the COD, with ethanol concentrations ranging from below detection to $2 \mathrm{~mL} / \mathrm{L}$ in the effluent. Acetic acid is the second organic component that contributes significantly to the COD of winery effluent and was found to occur at concentrations as high as $0.4 \mathrm{~mL} / \mathrm{L}$. The maximum COD recorded was $3760 \mathrm{mg} / \mathrm{L}$. Similarly, ethanol was found to be the major constituent in Cellar 2, contributing approximately $91 \%$ of the COD and rising to concentrations of as high as 3.75 $\mathrm{mL} / \mathrm{L}$. Acetic acid was found to have concentrations as high as $0.75 \mathrm{~mL} / \mathrm{L}$ on certain days. The maximum COD of $7000 \mathrm{mg} / \mathrm{L}$ 
found at Cellar 2 is well within the normal range expected for a winery of this size (Sheridan et al., 2005). The difference between cellars is due to the natural variances in the process, the degree of spillage, and the type of spillage, namely whether juice or wine was spilt. The data support the postulation that acetic acid would be the primary contributor to a decrease in $\mathrm{pH}$ and that ethanol is the primary component of the COD. In both cellars, the calculated COD was found to be similar to the measured COD, which is a valuable indicator of the accuracy of both the COD test, as well as the GC method.

For both cellars, the average $\mathrm{pH}$ of the effluent during the harvest period was approximately 4.9. This value is outside the lower limit for legal disposal without some form of treatment in South Africa (Government Gazette, 2001). Since most of the acidic components of the effluent are readily biodegradable, chemical $\mathrm{pH}$ control would unlikely be required if the effluent was treated by whatever method.

For both cellars the concentration of potassium in the effluent ranged from approximately $20 \mathrm{mg} / \mathrm{L}$ to $220 \mathrm{mg} / \mathrm{L}$, and the value was strongly dependent on the time of year and the intensity of the harvest season. The presence of potassium was very likely related to the natural quantities of potassium in the grapes.

Sodium concentrations ranged from approximately $25 \mathrm{mg} / \mathrm{L}$ to $80 \mathrm{mg} / \mathrm{L}$ in the effluent from Cellar 1 , and from approximately $10 \mathrm{mg} / \mathrm{L}$ to $125 \mathrm{mg} / \mathrm{L}$ in the effluent emanating from Cellar 2. The concentrations were roughly independent of the harvest and associated mostly with the background concentration of $\mathrm{Na}$ in the fresh water used in the cellar, as well as the ad hoc use of cleaning agents. The use of sodium-based cleaning agents by wineries must be discouraged, since the longevity of sodium cations in the environment is a concern, especially as it causes sodicity of the soil. Potash (potassium hydroxide) is as effective as sodium hydroxide for cleaning the precipitated tartrates from tanks, and potassium is also absorbed by the environment if it is released.

Whilst other components, such as longer $\left(\mathrm{C}_{3}, \mathrm{C}_{4}, \mathrm{C}_{5}\right)$ carboxylic acids, other organic acids and phenolic components, are present in winery effluent, they are not significant for determining/sizing a treatment method/plant. The peak of the effluent strength (maximum COD) occurred in the middle of the harvest period. This suggests that two weeks of intensive sampling on either side of the middle of the harvest period should be sufficient accurate to characterise the peak effluent strength.

The winemaking process is inherently varied (Sheridan, 2003), and this variation is evident in the data presented here. Not all grape varietals ripen at the same time, and thus there are lulls in the harvest season. When this occurs, cellar washing is often made a priority, and on these days the quantity of effluent is greater and the concentration of sodium is higher. On days when harvesting occurs, wine and juice transfer is most prevalent, and these are the days when the organic components of the effluent are likely to be the most significant. Since each winery has its own associated set of grape varietals and its own unique climatic conditions, it may not be possible to extrapolate this data to other cellars.

\section{CONCLUSIONS}

The findings presented here profile the effluent from two different wineries over different periods of time. In the first section, the effluent is profiled for the duration of a year, and the peak effluent was found to occur during the harvest period. In the second section it was shown that the peak effluent occurs approximately midway through the harvest.

Winery effluent poses a problem in terms of disposal without treatment because of the high concentration of ethanol present in it. This quantity of ethanol may indicate process inefficiencies (especially the loss of wine). If the final product from the winery is $13 \%(\mathrm{v} / \mathrm{v})$ ethanol and the effluent stream is $0.4 \%(\mathrm{v} / \mathrm{v})$ ethanol, as measured in this study, a significant loss of product could have been incurred if a large quantity of effluent was produced. Without cleaner production strategies, or adherence to waste minimisation programmes, the ethanol (together with the other $10 \%$ of the COD of the raw effluent) will have to be treated before disposal.

Whilst the data generated in this study provide detailed information on the composition of raw winery effluent, they are also useful for determining those specific kinetic rate constants that need measurement in order to determine the degradation rate of winery effluent during treatment. However, the correlation between COD and ethanol concentration may no longer hold once the process of effluent degradation has begun. The data and correlations presented here are useful, however, to indicate trends as they occur over the course of a year, and could serve to inform the design of effluent treatment for the peak effluent periods of the year, as well as the likely composition and strength of that peak. The data could also be used for preparing an artificial effluent for research purposes.

\section{LITERATURE CITED}

Bustamante, M.A., Pareded, C., Moral, R., Moreno-Caselles, J., PerezEspinosa, A. \& Perez-Murcia, M.D., 2005. Uses of winery and distillery effluents in agriculture: characterisation of nutrient and hazardous components. Water Sci. Technol. 51(1), 145-151.

Chapman, J., 1996. Cleaner production for the wine industry handbook. South Australia Wine and Brandy Industry Association, Adelaide, South Australia.

Cheung, L.M., Cheung, P.C.K. \& Ooi, V.E.C., 2003. Antioxidant activity and total phenolics of edible mushroom extracts. Food Chem. 2(81), 249-255.

Colin, T., Bories, A., Sire, Y. \& Perrin, R., 2005. Treatment and valorisation of winery wastewater by a new biophysical process (ECCF). Water Sci. Technol. 21(1), 99-106.

Government Gazette, 2001. Section 39 of the National Water Act of South Africa, General Authorisations. South Africa.

Kadlec, R.H. \& Knight, R.L., 1996. Treatment Wetlands. CRC Press, Boca Raton, Fl, USA.

Malandra, L., Wolfaardt, G., Zietsman, A. \& Viljoen-Bloom, M., 2003. Microbiology of a biological contactor for winery wastewater treatment. Water Res. 37, 4125-4134.

Marschner, H., 1983. General introduction to the mineral nutrition of plants. In: Lauchli, A. \& Bieleski, R.L. (eds). Inorganic plant nutrition, encyclopedia of plant Physiology, New Series, vol. 15A. p11-12; Springer-Verlag, BerlinHeidelberg, Germany.

Petruciolli, M., Duarte, J., Eusebio, A. \& Federici, F., 2001. Aerobic treatment of winery wastewater using a jet loop activated sludge reactor. Process Biochem. 37, 821-829. 
Radford, A., 2002. The composition of winery and distillery wastewater and effects on soil and water. Proc. SASEV Cellar \& Dist. Effl. Seminar. April 2002, ARC-Nietvoorbij, Stellenbosch, South Africa.

Shepherd, H.L., Tchobanoglous, G. \& Grismer, M.E., 2001. Time-dependent retardation model for chemical oxygen demand removal in a sub-surface flow constructed wetland for winery wastewater treatment. Water Environ. Res. 73(5), 597-606

Sheridan, C.M., 2003. A critical process analysis of wine production to improve cost, quality and environmental performance. Thesis, Stellenbosch University, Private Bag X1, 7602 Matieland (Stellenbosch), South Africa.
Sheridan, C.M., Bauer, F.F., Burton, S. \& Lorenzen, L., 2005. A critical process analysis of wine production to improve cost, quality and environmental performance. Water Sci. Technol. 51(1), 39-46.

Wood, A., 1995. Constructed wetlands in water pollution control: fundamentals to their understanding. Water Sci. Technol. 32(3), 21-29. 